\title{
Cyst of Canal of Nuck: 2 Case Reports
}

\author{
Suryagayathri $\mathrm{V}^{1^{*}}$, Alvin Vincent ${ }^{2}$, Sankar $\mathrm{S}^{3}$
}

${ }^{1,2}$ Junior Resident, Department of Pathology, Government Medical College, Kottayam, Kerala, Pin: 686008, India

${ }^{3}$ Professor and HOD, Department of Pathology, Government Medical College, Kottayam Kerala, Pin: 686008, India

DOI: $10.36347 /$ simcr.2020.v08i03.031

| Received: 26.02.2020 | Accepted: 04.03.2020 | Published: 19.03.2020

*Corresponding author: Suryagayathri V

Abstract

Canal of Nuck is formed by the evagination of parietal peritoneum into the inguinal canal in a female. It is homologous to the processus vaginalis in male. Failure of obliteration of this can result in an indirect inguinal hernia or hydrocele of the canal. Though this entity is rare, hydocele of canal of Nuck can be considered as a differential diagnosis in the cystic swellings in the inguinal region in a female.

Keywords: Canal of nuck, inguinal region, Hydrocele.

Copyright @ 2020: This is an open-access article distributed under the terms of the Creative Commons Attribution license which permits unrestricted use, distribution, and reproduction in any medium for non-commercial use (NonCommercial, or CC-BY-NC) provided the original author and source are credited.

\section{INTRODUCTION}

Canal of Nuck is a small evagination of the parietal peritoneum which accompanies the round ligament through the internal inguinal ring into the inguinal canal in a female [1]. It is homologous to the processus vaginalis in male [2]. Failure of obliteration of this can result in an indirect inguinal hernia or hydrocele of the canal. Most of the cases which are described are in the pediatric age group and rarely seen in adults [3]. We report 2 patients with cyst of canal of nuck (one adult and one pediatric).

\section{CASE REPORTS}

CASE 1: A 4 year old female child presented to the OPD with history of slow growing groin swelling on the right side since 6 months. On examination, there was a $2 \times 1 \mathrm{~cm}$ right sided inguinal swelling, cystic in nature, transilluminent and reducible. On sonography right inguinal small tubular structure of size $1.5 \times 0.4$ $\mathrm{cm}$ with hernial defect of size $3.7 \mathrm{~mm}$ on minimal straining was found. Patient underwent surgical exploration. Intraoperatively sac was present with contents and was sent for histopathological examination. Specimen received was as multiple tissue bits.

CASE 2: A 48 year old woman presented with complaints of swelling in left inguinal region for 4 years with gradual increase in size. Swelling was associated with intermittent pain. Ultrasonogram showed a $6 \times 2.5 \times 3 \mathrm{~cm}$, multiloculated, well defined, lobulated, cystic lesion in the subcutaneous plane in left inguinal region extending to pubic region.

Surgical exploration was done. Specimen received was an elongated cystic mass weighing $30 \mathrm{gm}$ and measuring $10 \times 3.5 \times 3 \mathrm{~cm}$. Cut section showed multiple cysts with yellowish serous fluid and smooth inner wall (Fig $1 \& 2$ ).

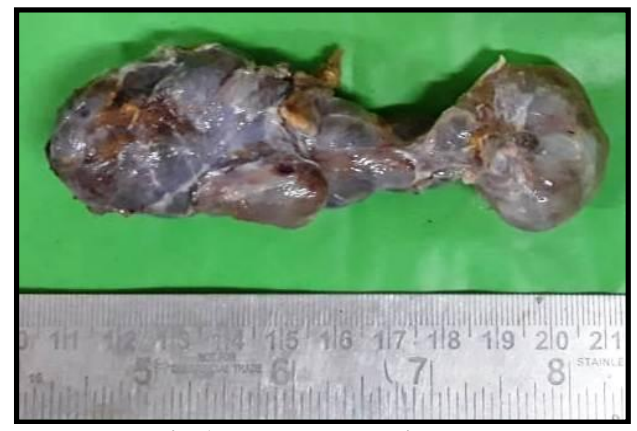

Fig-1: Elongated cystic mass

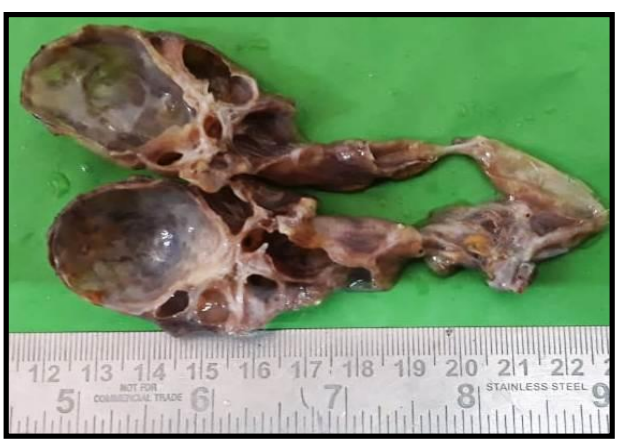

Fig-2: Cut section showing multiple cysts with smooth inner wall 
Microscopy of both the cases showed cystic spaces lined by mesothelium and wall showed fibrous tissue with smooth muscle in between (Fig 3 \& 4). Trichrome stain was positive for smooth muscle. Mesothelial lining cells were positive for calretinin in immunohistochemistry. A diagnosis of CYST OF CANAL OF NUCK was made in both the cases.

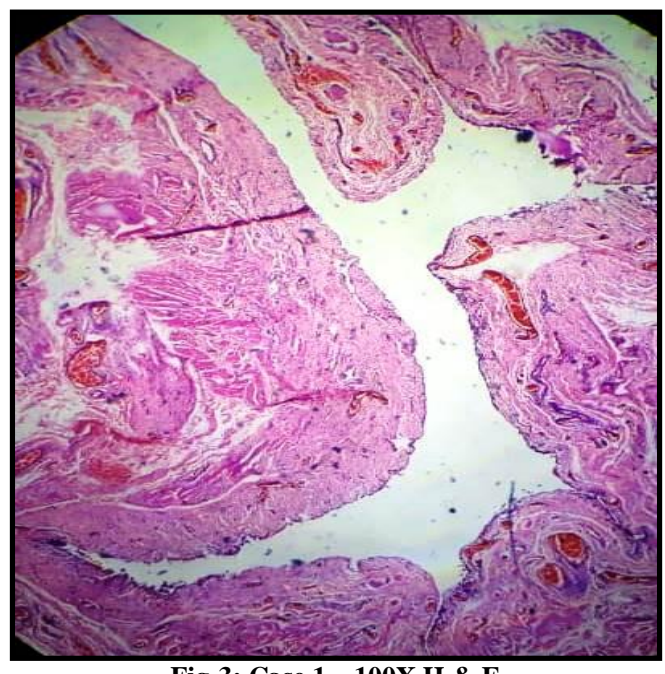

Fig-3: Case 1 - 100X H \& E

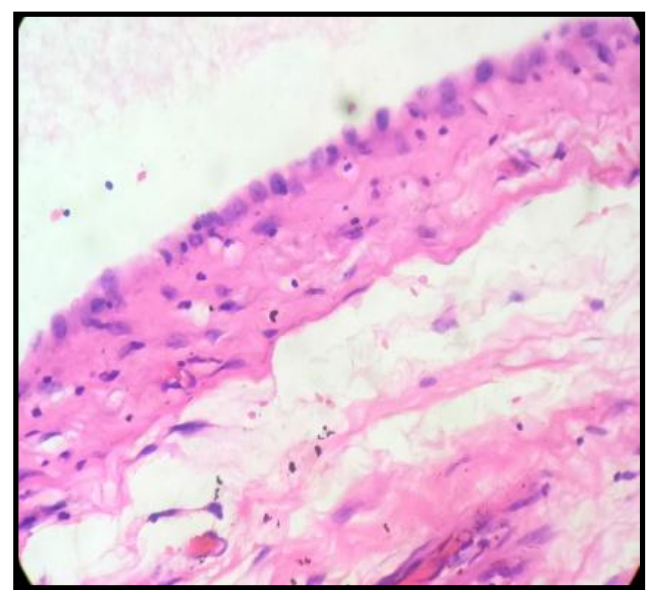

Fig-4: Case 2 - 400X H \& E

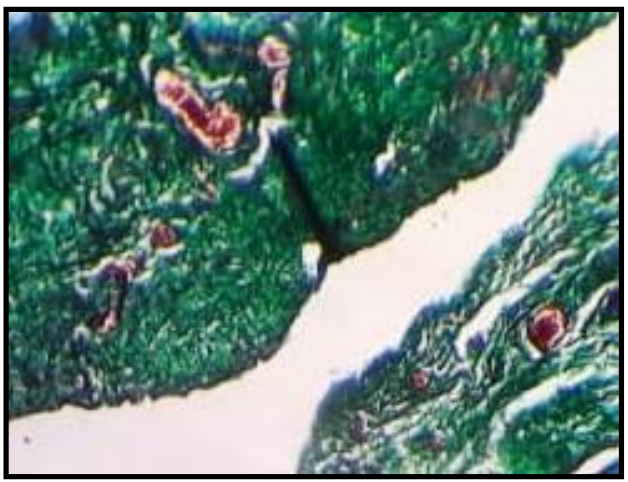

Fig-5: Case 1 - Trichrome Staining

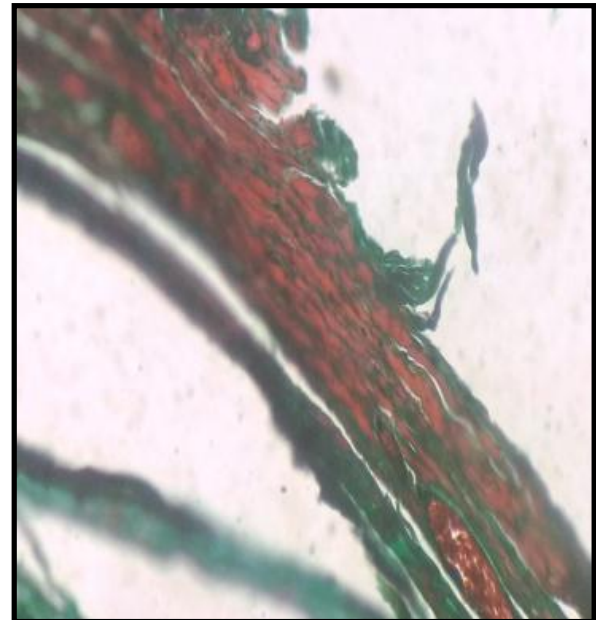

Fig-6: Case 2 - Trichrome Staining

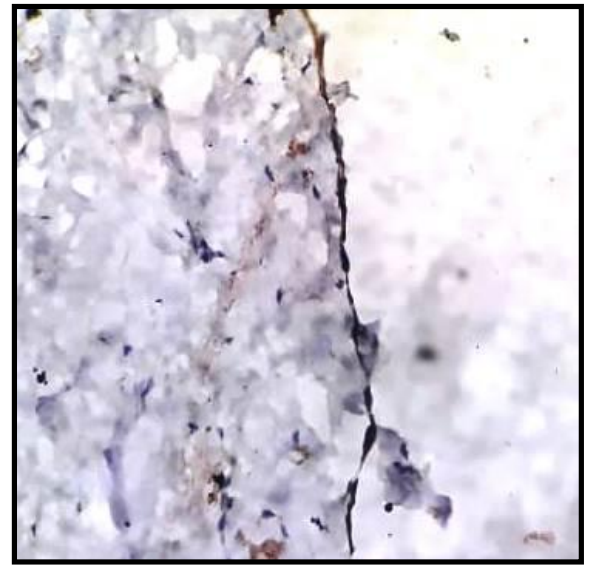

Fig-7: Case 1 - Calretinin positive

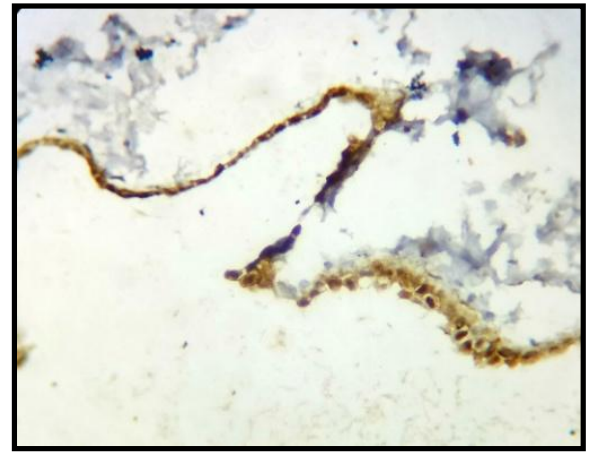

Fig-8: Case 2 - Calretinin positive

\section{DISCUSSION}

Portion of the parietal peritoneum accompanying the round ligament through the inguinal canal in female forms the Canal of Nuck [4]. It is usually obliterated in the first year of life. Indirect inguinal hernia or hydrocele can result from the incomplete obliteration of this canal [4].

Canal of Nuck was first described by Antonn Nuck, a Dutch Anatomist in 1691[3]. Hydrocele of canal of Nuck is a rare condition which is caused probably due to imbalance between the secretion and absorption of the secretory lining [2]. 
Although most of the cases reported are those of pediatric age group, it may rarely occur in adults also. Clinical presentation is usually as a painless swelling in the inguinal region. Occasionally, a dull aching pain may be present [3]. This can create a clinical suspicion of other conditions like hernia, cysts, abscess, tumours and enlarged lymph nodes [2]. Radiological investigations may help in the diagnosis [1]. However, the final diagnosis is made during surgery by the location and is confirmed by the histopathological examination [3]. The canal of Nuck derived from the abdominal wall is divided into two layers. Outer wall consists of varying thickness of fibrous tissue with smooth muscle fibers and inner wall consists of single layer of mesothelial cells [2]. Secretion - Absorption imbalance can be caused by infection, injury or inappropriate lymphatic drainage [2]. We report these cases due to their rarity. Hydocele of canal of Nuck is to be considered as a differential diagnosis in the cystic swellings in the inguinal region in a female.

\section{REFERENCE}

1. Rembhia.SU, Aeyar P. Hydrocele of canal of Nuck: a case report. International Surg Journal. 2015; 2:396-397.

2. Kwing Seog Kim, Jun Ho Choi. Hydrocele of canal of Nuck a female adult; Arch Plastic Surgery. 2016; 43:476-478.

3. Lombardo V, Cara G D. Surgical treatment of cyst of the canal of Nuck: report of a case. World Journal of Surgical research. 2017; 8.

4. Choi YM, Lee GM, Yi JB, Yoon KL, Shim KS, Bae CW. Two cases of female hydrocele of the canal of nuck. Korean J Pediatr. 2012; 55:143-6. 